\title{
Using semi-natural and simulated habitats for seed germination ecology
}

\author{
Simon Kallow ${ }^{1}$, Katrijn Quaghebeur ${ }^{1}$, Bart Panis ${ }^{2}$, Steven Janssens ${ }^{3}$, John B. Dickie ${ }^{4}$, \\ Lavernee Gueco $^{5}$, Rony Swennen ${ }^{1}$, and Filip Vandelook ${ }^{3}$ \\ ${ }^{1} \mathrm{KU}$ Leuven Faculty of Bioscience Engineering \\ ${ }^{2}$ Catholic University College Leuven \\ ${ }^{3}$ Botanic Garden Meise \\ ${ }^{4}$ Royal Botanic Gardens Kew \\ ${ }^{5}$ University of the Philippines Los Banos
}

July 15, 2021

\begin{abstract}
1. Ecologically meaningful seed germination experiments are constrained by access to seeds and relevant environments for testing at the same time. This is particularly the case when research is carried out far from the native area of the studied species. 2. Here, we demonstrate an alternative - the use of glass houses in botanic gardens as simulated-natural habitats to extend the ecological interpretation of germination studies. Our focal taxa were banana crop wild relatives (Musa acuminata subsp. burmannica, M. acuminata subsp. siamea and M. balbisiana), native to tropical and subtropical Southeast Asia. Tests were carried out in Belgium, where we performed germination tests in relation to exposure to sun and foliage-shading, seed burial-depth in different heated glass house compartments, as well as seed survival and dormancy release in the soil. We anchored the interpretation of these studies by also conducting an experiment in a semi-natural habitat in the species native range (M. balbisiana - Los Baños, the Philippines), where we tested germination responses to exposure to the sun and shade. Using temperature data loggers, we determined temperature dynamics suitable for germination in both these settings. 3 . In semi-natural and simulated-natural habitats, seeds germinated in response to exposure to direct solar radiation. Seed burialdepth had a significant but marginal effect by comparison, even when seeds were buried to $7 \mathrm{~cm}$ in the soil. Temperatures at sun-exposed compared to shaded environments differed by only a few degrees Celsius. Maximum temperature of the period prior to germination was the most significant contributor to germination responses and germination increased linearly above a threshold of $23^{\circ} \mathrm{C}$ to the maximum temperature in the soil (in simulated natural habitats) of $35^{\circ} \mathrm{C} .4$. Glass houses can provide useful environments to aid interpretation of seed germination responses to environmental niches.
\end{abstract}

\section{Using semi-natural and simulated habitats for seed germination ecology}

Simon Kallow ${ }^{1,2,3^{*}}$, Katrijn Quaghebeur ${ }^{2,3}$, Bart Panis ${ }^{2,4}$, Steven B. Janssens ${ }^{3,5}$, John Dickie ${ }^{1}$, Lavernee Gueco $^{6}$, Rony Swennen ${ }^{2,7}$, Filip Vandelook ${ }^{3}$

${ }^{1}$ Royal Botanic Gardens Kew, Millennium Seed Bank, Wakehurst, Ardingly, Sussex, RH17 6TN, UK

${ }^{2}$ Katholieke Universiteit Leuven, Department of Biosystems, Willem de Croylaan 42, 3001, Leuven, Belgium

${ }^{3}$ Meise Botanic Garden, Nieuwelaan 38, 1860 Meise, Belgium 
${ }^{4}$ Bioversity International, Willem de Croylaan 42, 3001, Leuven, Belgium

${ }^{5}$ Katholieke Universiteit Leuven, Biology Department, Kasteelpark Arenberg 31, 3001 Leuven, Belgium

${ }^{6}$ National Plant Genetic Resources Laboratory, Institute of Plant Breeding, College of Agriculture and Food Science, University of the Philippines, Los Baños, 4031 Laguna, Philippines

7 International Institute of Tropical Agriculture, c/o Nelson Mandela African Institution of Science and Technology, Arusha, Tanzania

Corresponding author: Simon Kallow (S.Kallow@kew.org)

Running title: Seed ecology in non-natural habitats

Word count: 6821

\section{Keywords}

Botanic gardens, crop wild relatives, gap detection, seed germination

\section{Abstract}

1. Ecologically meaningful seed germination experiments are constrained by access to seeds and relevant environments for testing at the same time. This is particularly the case when research is carried out far from the native area of the studied species.

2. Here, we demonstrate an alternative - the use of glass houses in botanic gardens as simulated-natural habitats to extend the ecological interpretation of germination studies. Our focal taxa were banana crop wild relatives (Musa acuminata subsp. burmannica, M. acuminata subsp. siamea and M. balbisiana ), native to tropical and subtropical Southeast Asia. Tests were carried out in Belgium, where we performed germination tests in relation to exposure to sun and foliage-shading, seed burial-depth in different heated glass house compartments, as well as seed survival and dormancy release in the soil. We anchored the interpretation of these studies by also conducting an experiment in a seminatural habitat in the species native range ( $M$. balbisiana - Los Baños, the Philippines), where we tested germination responses to exposure to the sun and shade. Using temperature data loggers, we determined temperature dynamics suitable for germination in both these settings.

3. In semi-natural and simulated-natural habitats, seeds germinated in response to exposure to direct solar radiation. Seed burial-depth had a significant but marginal effect by comparison, even when seeds were buried to $7 \mathrm{~cm}$ in the soil. Temperatures at sun-exposed compared to shaded environments differed by only a few degrees Celsius. Maximum temperature of the period prior to germination was the most significant contributor to germination responses and germination increased linearly above a threshold of $23^{\circ} \mathrm{C}$ to the maximum temperature in the soil (in simulated natural habitats) of $35^{\circ} \mathrm{C}$.

4. Glass houses can provide useful environments to aid interpretation of seed germination responses to environmental niches.

\section{Introduction}

Ideally, seed germination ecology studies are carried out in both natural habitats (NHs) and laboratory conditions (LCs) (Baskin \& Baskin 2014). This allows variables affecting germination to be clearly identified and ecologically interpreted. Interpretation is usually made in relation to spatial and temporal niches in NHs, or perhaps semi-natural habitats (Semi-NHs) (Table 1).

Table 1. Descriptions of environments for seed germination studies. 


\begin{tabular}{|c|c|c|c|c|}
\hline Name & Definition & $\begin{array}{l}\text { Germination } \\
\text { example }\end{array}$ & Control level & $\begin{array}{l}\text { Interpretation } \\
\text { level }\end{array}$ \\
\hline $\begin{array}{l}\text { Natural habitat } \\
(\mathrm{NH})\end{array}$ & $\begin{array}{l}\text { Areas composed } \\
\text { of viable } \\
\text { assemblages of } \\
\text { plant and/or } \\
\text { animal species of } \\
\text { largely native } \\
\text { origin and/or } \\
\text { where human } \\
\text { activity had not } \\
\text { essentially } \\
\text { modified an area's } \\
\text { primary ecological } \\
\text { functions and } \\
\text { species } \\
\text { composition. a }\end{array}$ & $\begin{array}{l}\text { (Dinsdale, Dale \& } \\
\text { Kent 2000) }\end{array}$ & & \\
\hline $\begin{array}{l}\text { Semi-natural } \\
\text { habitat } \\
(\text { Semi-NH) }\end{array}$ & $\begin{array}{l}\text { Ecological } \\
\text { assemblages that } \\
\text { have been } \\
\text { substantially } \\
\text { modified in their } \\
\text { composition, } \\
\text { balance or } \\
\text { function by } \\
\text { human activities. } \\
\text { a }\end{array}$ & $\begin{array}{l}\text { (Stephens, } \\
\text { Castro-Morales \& } \\
\text { Quintana- } \\
\text { Ascencio } \\
2012)\end{array}$ & & \\
\hline $\begin{array}{l}\text { Simulated natural } \\
\text { habitat } \\
\text { (Simulated-NHs) }\end{array}$ & $\begin{array}{l}\text { A wholly } \\
\text { constructed } \\
\text { environment, made } \\
\text { to resemble a NH. }\end{array}$ & & & \\
\hline $\begin{array}{l}\text { Laboratory } \\
\text { conditions (LC) }\end{array}$ & $\begin{array}{l}\text { A un-natural } \\
\text { environment, } \\
\text { variables are } \\
\text { clearly defined } \\
\text { and controlled. }\end{array}$ & $\begin{array}{l}\text { (Mattana et al. } \\
\text { 2016) }\end{array}$ & & \\
\hline
\end{tabular}

${ }^{\mathrm{a}}=($ European Investment Bank 2018)

In LC germination experiments, such as those using incubators, most variables are kept constant (e.g. light intensity, sowing medium, water-availability, timing of diurnal temperature cycle), and one or two are manipulated with a few combinations (e.g. three or four temperatures of diurnal cycles). Researchers select the conditions of variables based on knowledge from $\mathrm{NH}$ microclimates, but in reality, these are notoriously difficult to exactly define (e.g. Dinsdale, Dale \& Kent 2000). Indeed, important variables may inadvertently be omitted from experimental designs. Interpretation of LC experiments in an ecologically meaningful way is difficult because it will be based on many assumptions, both in selecting variables to test and extrapolating interpretation to NHs - especially if NHs have not been adequately studied.

By contrast, in NH experiments, many, often unknown, variables interplay, one or two of which may be controlled. If researchers were to control all combinations of $\mathrm{NH}$ variables in LCs they would soon run out of seeds, time and space. Interpretation of $\mathrm{NH}$ experiments depends on dynamically recorded variables that 
cannot be well controlled, some even being irrelevant to germination ecology. It goes without saying that $\mathrm{NH}$ experiments can only truly be performed in regions where the plant is native, whereas LC experiments can be carried out anywhere with suitable equipment.

Alternatives to $\mathrm{NH}$ and $\mathrm{LC}$ are semi-natural habitats (Semi-NHs) or simulated natural environments (Simulated-NHs). Examples of Semi-NHs include fields or farm edges, in or close to a species' native region. The term simulated-natural environment (or habitat as used here) was used by Kaeberlein et al. (2002) to define an environment of natural seawater and sediment the authors placed in aquariums to culture previously 'uncultivable' marine microorganisms. Such Simulated-NHs are less controlled than LCs, but allow better interpretation of findings and may include important factors that are not well understood or known and so may inadvertently be omitted from LCs. Glass houses, such as those in botanic gardens, are examples of Simulated-NHs, as they mimic NHs and variables are not well under control.

In botanic gardens, living collections are often arranged according to geographic plant communities, each compartment or grouping representing a pseudo or Simulated-NH. These living collections are a valuable resource in studying plant ecology, particularly when NHs are challenging to access (Perez et al. 2019). Many botanic gardens also hold seed banks (469 gardens), and carry out seed or spore research (155 gardens) (BGCI 2021). As botanic gardens are biased towards temperate regions in the Northern hemisphere (Mounce, Smith \& Brockington 2017), there is opportunity to enhance interpretation of seed germination studies using botanic gardens as Simulated-NHs when it is not possible to do so in native regions (Faraji \& Karimi 2020).

Wild banana species (Musa L.) are native to tropical and subtropical Asia to the western Pacific (Govaerts \& Häkkinen 2006). Their fruit contains many hard darks seeds, 3-7 $\mathrm{mm}$ in diameter (Chin 1996). The conditions for germination are not well understood and germination is notoriously inconsistent and often very low (Kallowet al. 2020; Panis, Kallow \& Janssens 2020; Singh et al.2021). LC experiments show a requirement for alternating temperatures (Stotzky \& Cox 1962; Kallow et al. 2021), but no NH experiments have been executed to interpret this. For instance, is this requirement a gap or depth detection mechanism affected by microclimates? And do species respond differently?

Understanding seed germination ecology of wild bananas is not only of ecological interest, it is also important for global food security. Seed banking crop wild relatives efficiently protects genetic material and makes it available for phenotyping and breeding (Dempewolf et al.2017), it is included in UN Sustainable Development Target 2.5 (UN General Assembly 2015). Optimized germination is a vital component of seed bank management and breeding - without it, viability is difficult to monitor and access to plants for research and breeding is constrained (FAO 2014; Batte et al. 2019; Amah et al. 2020).

In the present study we examined germination responses in a Semi-NH and Simulated-NHs of the two primary crop wild relatives of banana:Musa acuminata (subsp. siamea N.W. Simmonds, and subsp.burmanicca N.W. Simmonds), and M. balbisiana Colla (De Langhe et al. 2009). Specifically, we aim to answer the following questions that cannot be answered in LCs: (1) What environments stimulate or inhibit Musa germination? (2) Are Musa seeds dormant, and if so how is this broken in the environment? (3) CanMusa seeds remain viable in the soil?

\section{Materials and methods}

1. Semi-natural habitat (nursery, Philippines)

2. Plant material

We collected a bunch (an infructescence) of Musa balbisiana(accession GB61996) containing seeds from the field genebank at the National Plant Genetic Resources Laboratory (NPGRL), Institute of Plant Breeding, University of the Philippines, Los Baños. Seeds were extracted by opening fruit and washing seeds in flowing water to remove all pulp. Seeds were then left on a tray in the laboratory to surface dry for seven days prior to sowing. 
Table 2. Accessions used for germination experiments in simulated natural environments, V= viability percentage from embryo rescue tests in 2019 and 2020.

\begin{tabular}{lllll}
\hline Accession & Taxa & Source & Native distribution ${ }^{\text {b }}$ & Year col \\
\hline GB61996 & M. balbisiana & Philippines & Trop. \& Subtrop. Asia & 2019 \\
bur60 & M. acuminata subsp. burmannica & Guadeloupe & SW. India, China (S. Yunnan) to Indo-China & 2014 \\
sia61-63 & M. acuminata subsp. siamea & Guadeloupe & Indo-China to N. Pen. Malaysia & 2014 \\
bal106 & M. balbisiana & China (Hainan) & Trop. \& Subtrop. Asia & 2017 \\
bal115 & M. balbisiana & Nigeria & Trop. \& Subtrop. Asia & 2019 \\
\hline
\end{tabular}

$\mathrm{b}=$ Govaerts and Häkkinen, 2006

Solar radiation and substrate

We used the nursery of the NPGRL (latitude 14.153, longitude 121,262), as a Semi-NH for germination testing. We used locations either exposed to solar radiation ('sun') - only lightly shaded in the fine screen house, or without direct exposure to solar radiation ('shade') - in an open-sided cabinet covered at the top also in the screen house. We sowed seeds in plastic trays $(100 \times 40 \times 10 \mathrm{~cm}$ ), using two types of substrate (clay loam soil and fine sand), and covered seeds with $5 \mathrm{~mm}$ of substrate. Two replicates of 200 seeds were used for each treatment combination. We recorded the temperature and relative humidity (RH), every 20 minutes for 55 days in sowing locations using data loggers (Tinytag View 2, Gemini Data Loggers, Chichester, UK). Trays were watered daily, emergent seedlings were recorded and removed weekly. The test was concluded after 55 days.

Simulated-natural environment (glass house compartments, Belgium)

\section{Plant material}

We studied germination responses in Simulated-NHs in relation to foliage-shading and seed burial-depth using two Musa species (total three taxa, Table 2). Seeds were selected from the collection of Bioversity International/KU Leuven (Leuven, Belgium) and were supplied for scientific use with a phytosanitary and origin certificate from China (Hainan), Guadeloupe, and Nigeria. Seeds were from open-pollinated accessions in living collections and were air shipped from source to Leuven as complete bunches, where they were extracted as described above, apart from bal106 which were provided as extracted and cleaned seeds transported to Leuven, Belgium. After ambient drying, seeds were placed in the refrigerator in paper bags, until 2019 when they were sealed in aluminum bags and stored in the refrigerator at approximately $6 \%$ moisture content, fresh weight basis. Viability was assessed prior to sowing (both in 2019 and 2020) using ER (method described by Kallowet al. 2020).

\section{Foliage-shading and seed burial-depth}

We selected a total of six Simulated-NHs for germination tests. Five were in three compartments of Meise Botanic Gardens glass house, Belgium (latitude 50.925, longitude 4.330), and one in the full-ground glass house of KU Leuven, Belgium (latitude 50.860, longitude 4.680). Simulated NHs were selected to represent various heating regimes in different compartments and levels of foliage-shading/exposure to solar radiation (Table 3). All compartments included living banana specimens.

Seeds were sown in square plastic pots $(9 \times 9 \times 10 \mathrm{~cm})$, at two burial-depths $(1 \mathrm{~cm}$ and $7 \mathrm{~cm}$ from the surface), using potting compost (Peltracom, composition: $70 \%$ white peat and $30 \%$ black peat; pH: 5.5 - 6.5; particle size: $0-10 \mathrm{~mm}$ ). Two replicates of 30 seeds of each accession were sown in separate pots which were then also buried to be level with soil surface. Data loggers (Tinytag Transit 2 TG4080, Gemini Data Loggers, Chichester, UK) were buried at each location and burial-depth. Loggers were set to record temperatures every 20 minutes. Additionally in 2020, loggers were placed at the soil surface to record light intensity and surface temperature (HOBO Pendant MX2202, Onset, Cape Cod, Massachusetts, US). Germination was 
monitored weekly and emergent seedlings were recorded and removed. Seeds were sown in early March 2019, and again in early March 2020s, this is the end of the winter/start of the spring season in Belgium (mean outdoor temperature $6.4^{\circ} \mathrm{C}$, climate-data.org). The experiment was concluded in March 2021.

Table 3 . Summary heating regimes of glass house compartments used, temperatures are the thermostat temperature below which artificial heating is instigated.

\begin{tabular}{lllll}
\hline Compartment name & Institution & Exposure & Day $\left({ }^{\circ} \mathrm{C}\right)$ & Night $\left({ }^{\circ} \mathrm{C}\right)$ \\
\hline Leuven & KU Leuven & Exposed & 15 & 15 \\
Mabundu & Meise Botanic Gardens & Exposed & 25 & 25 \\
Tropical & Meise Botanic Gardens & Shaded & 20 & 18 \\
Tropical & Meise Botanic Gardens & Exposed & 20 & 18 \\
Spring & Meise Botanic Gardens & Shaded & 10 & 8 \\
Spring & Meise Botanic Gardens & Exposed & 10 & 8 o \\
\hline
\end{tabular}

\section{Dormancy and stratification in the soil}

To assess dormancy and dormancy loss in the soil (stratification), seeds from the two M. balbisiana accessions (bal106 and bal115) were incubated at alternating $35^{\circ} \mathrm{C}$ in the light for 6 hours and $20^{\circ} \mathrm{C}$ in the dark for 18 hours (based on Stotzky, Cox \& Goos 1961; Kallow et al. 2021). Additionally, seeds were buried at two of the cooler Simulated-NHs (Spring/Exposed and Leuven/Exposed) in March 2019 and exhumed each month for a total of three months and placed in the incubator conditions described. Seeds were enclosed in small nylon meshed bags and were buried at $7 \mathrm{~cm}$ depth in March 2019. Two replicates of 30 seeds were used for each treatment and accession. For incubation, seeds were sown on moist sand (50 g fine sand, $14 \mathrm{ml}$ deionized water) in Petri dishes (9 cm diameter), sealed in plastic bags, at Meise Botanic Garden. Germinated seedlings of these were recorded and removed weekly for two months. Germination was counted as radicle emergence to $2 \mathrm{~mm}$.

\section{Survival in the soil}

At the end of the experiment, seeds planted at shaded Simulated-NHs (locations that showed no emergent seedlings in results) were extracted from pots and tested for viability using a tetrazolium chloride staining test or by incubation. Seeds sown in both 2019 and 2020 were used. Pots containing seeds were removed, seeds were separated from compost by sieving under running water. Extracted seeds from the first replicate of each treatment were tested for viability with tetrazolium chloride (TTC) with a maximum of 20 seeds. The TTC tests were carried out on embryos carefully extracted from seeds, using $0.5 \%$ TTC solution buffered to pH 7 (method described by Kallow et al. 2020), incubated at $24^{\circ} \mathrm{C}$ for 24 hours in the dark. Extracted seeds from the second replicate were sowed in Petri dishes on top of moist sterilized potting compost (Peltracom, composition: $70 \%$ white peat and $30 \%$ black peat; pH: 5.5- 6.5 ; particle size: $0-10 \mathrm{~mm}$ ) and placed in an incubator at a 24-hour cycled temperature pattern (based on temperature readings from Los Baños, the Philippines - sun exposed site, Fig. 1a). Seeds in the incubator were monitored every two weeks, for a maximum of five weeks. If very few seeds were extracted from the soil for a replicate, TTC tests were prioritized above incubator germination tests.

\section{Data analysis}

We calculated summary indices for germination tests using the GerminaR package in R (Lozano-Isla, BenitesAlfaro \& Pompelli 2019). These included final germination percentage (GRP, \%) (Labouriau \& Valadares 1983), mean germination time (MGT, days) (Czabator 1962) and synchronization index (SYN, simultaneous germination within a replicate $=1$, no overlap between seeds of a replicate $=0)($ Primack 1980; Ranal \& Santana 2006).

We summarized data logger readings to extract the mean, maximum, minimum, and range (maximumminimum) during experimental 'cue periods'. In semi-NH this was the whole experimental period (55 days). 
In simulated-NHs for each year we summarized data filtered to include readings during 'cue periods' these were a period prior to the MGT of each replicate, set differently for shallow and deep planting based on the mean MGT for shallow and deep planting (shallow=32 days, deep=39 days). For locations with no germination, we used the first 39 days after sowing. We summarized logger readings for cue periods by calculating mean, maximum, minimum, range temperatures and light intensity readings (in 2020). We removed light intensity readings in the dark ( $<40$ lux), to account for changes in day/night length during seasons and did not calculate minimum light intensity as it would be the same in any site.

We then carried out redundancy analysis (RDA) of summarized logger data in cue periods, scaled to unit variance, against a corresponding matrix of factorial variables (species, compartment, exposure, depth) using thevegan R package (Oksanen et al. 2019). The minimum adequate RDA was found by comparison of Akaike Information Criterion (AIC), by adding variables to the minimum model.

Final germination, for each experiment, was assessed using counts of germinated seeds at the end of experiments against seeds that did not germinate, thus accounting for sample size variance. Sample sizes were adjusted in the analysis to only include viable seeds, estimated from ER results of that year, using the formula:

$$
\text { adjusted sample }=\text { seeds sown } x \text { viability of year sown }
$$

These data were used in generalized linear modelling (GLMs) of binomial data with logit link function. If overdispersion was present in binomial GLMs we used quasibinomial error structure. Minimum adequate models (MAM) were produced by removing variables from maximum models after comparisons with ANOVA and $X^{2}$ test. Estimated marginal means were made from models and used for post-hoc analysis using the emmeans R package (Lenth 2020). Additionally, we used GLMs for factorial variables on MGT and SYN using gamma error structure. We assessed the effect of environmental variables in cue periods on binomial germination outcomes using GLMs as described. Following this we tested variables for breakpoints to assess temperature thresholds or optimums. We did this on GLMs produced for each microclimate variable separately by using the algorithm with bootstrapping in thesegmented $\mathrm{R}$ package (Muggeo 2017). We used starting points estimated by plotting GRP against microclimate variables and trend lines using the non-linear regression method Loess.

We compared viability of seed survival of seeds exhumed after 1-2 years in the soil from the incubation test, TTC test, and maximum achieved from Simulated-NHs, against the original ER viability. We again used a binomial GLM for this, as described, and post-hoc contrasts against original ER with Dunnet tests. All analysis was performed in R (R Core Team 2020).

\section{Results}

\section{Effects of exposure to solar radiation and substrate on seed germination}

In the semi-NH exposure to direct solar radiation (sun) rather than shade, significantly increased germination rates $(z=20.963, p<0.001$, Fig. 1a). There was no significant effect of substrate on germination outcome according to the GLM. Final germination percentage in the sun was $72 \%$ (soil), $71 \%$ (sand) whereas in the shade it was $19 \%$ (soil), $12 \%$ (sand).

The MGT in the shade was $22 \pm 2$ days (mean, standard deviation, used hereafter), whereas in the sun it was slightly faster germinating in $18 \pm 2$ days, albeit only few seeds germinated in the shade. Synchronization index in the sun was $0.25 \pm 0.10$ and in the shade $0.27 \pm 0.07$. 


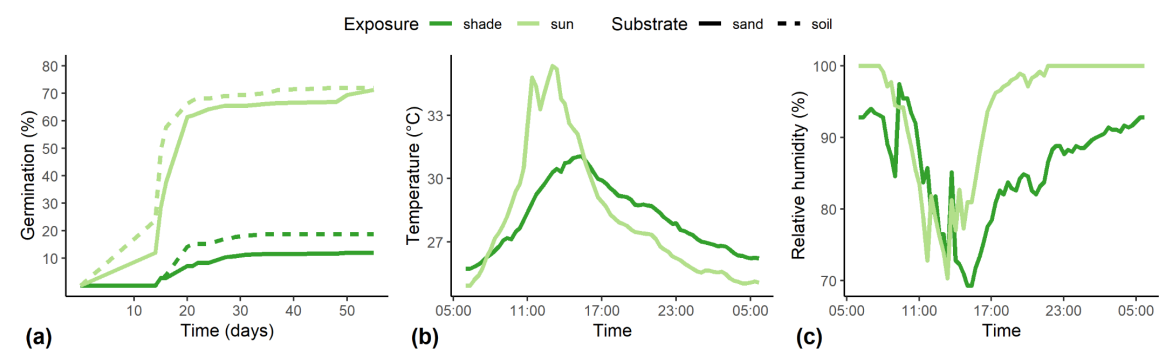

Fig. 1 (a) Cumulative germination of Musa balbisianaseeds sown in the semi-natural habitat (nursery, Los Baños, the Philippines), seeds were sown in the sun and shade, and in sand and soil ( $\mathrm{n}=200$, 2 replicates, mean values shown); (b) typical diurnal temperature and (c) relative humidity profiles logged at sowing site during germination test (Los Baños, the Philippines, $16^{\text {th }}$ November 2019).

Mean daily temperature in sun and shaded exposure was identical, but standard deviation was approximately $1^{\circ} \mathrm{C}$ greater in the sun $\left(27.3 \pm 2.8^{\circ} \mathrm{C}\right.$ sun, $27.3 \pm 1.9^{\circ} \mathrm{C}$ shade, Fig. $1 \mathrm{~b}$, Table 4$)$. Most notably, this relates to warmer maximum temperatures in the day of around $4^{\circ} \mathrm{C}$ in the sun. Mean diurnal range in the sun was therefore also greater $\left(8.9^{\circ} \mathrm{C}\right.$ sun, $5.1^{\circ} \mathrm{C}$ shade). Humidity in the sun and the shade was broadly similar, ranging diurnally between 75 and $100 \% \mathrm{RH}$ (Fig. 1c), a function of temperature.

Table 4. Summaries of the daily temperature and humidity recordings in the sun and shade at the location of the seed germination experiments. Values in brackets are standard deviations of means.

\begin{tabular}{lllllll}
\hline & Sun & Sun & Sun & Sun & Shade & Sha \\
\hline & Temperature $\left({ }^{\circ} \mathrm{C}\right)$ & Temperature $\left({ }^{\circ} \mathrm{C}\right)$ & Relative humidity $(\%)$ & Relative humidity $(\%)$ & Temperature $\left({ }^{\circ} \mathrm{C}\right)$ & Ten \\
Daily & Night & Day & Night & Day & Night & Day \\
Mean & $24.5( \pm 0.8)$ & $33.4( \pm 3.6)$ & $81.3( \pm 16.6)$ & $100( \pm 0.1)$ & $25.2( \pm 0.7)$ & 30.3 \\
Max & 26.2 & 42.2 & 100 & 100 & 26.7 & 38.5 \\
Min & 23.0 & 24.7 & 10.1 & 99.6 & 23.6 & 25.8 \\
\hline
\end{tabular}

Effects of foliage-shading and seed burial-depth on seed germination

Microclimate in simulated natural habitats

Cue period microclimate variables were constrained by the factors room and exposure in the minimum adequate RDA, and notably not by seed burial-depth or species $\left(r^{2}=0.88\right.$, Fig. 2). Exposure had the greatest influence on the microclimate $\mathrm{RDA}(\mathrm{df}=1, \mathrm{~F}=262.15, \mathrm{p}<0.001)$, room had more variance ( $\mathrm{df}=3$, $\mathrm{F}=144$. $\mathrm{P}<0.001$ ). Unsurprisingly, compartments with higher thermostat temperature thresholds (Table 3 ) were clustered with higher mean and minimum temperatures. These clusters did not include variables relating to extremes i.e., maximum temperatures, temperature ranges and soil surface values (for temperature and light). These were clustered separately and correspond to exposed microclimates. Shaded microclimates varied less than exposed, hence the different shapes of ellipses in Fig. 2. 


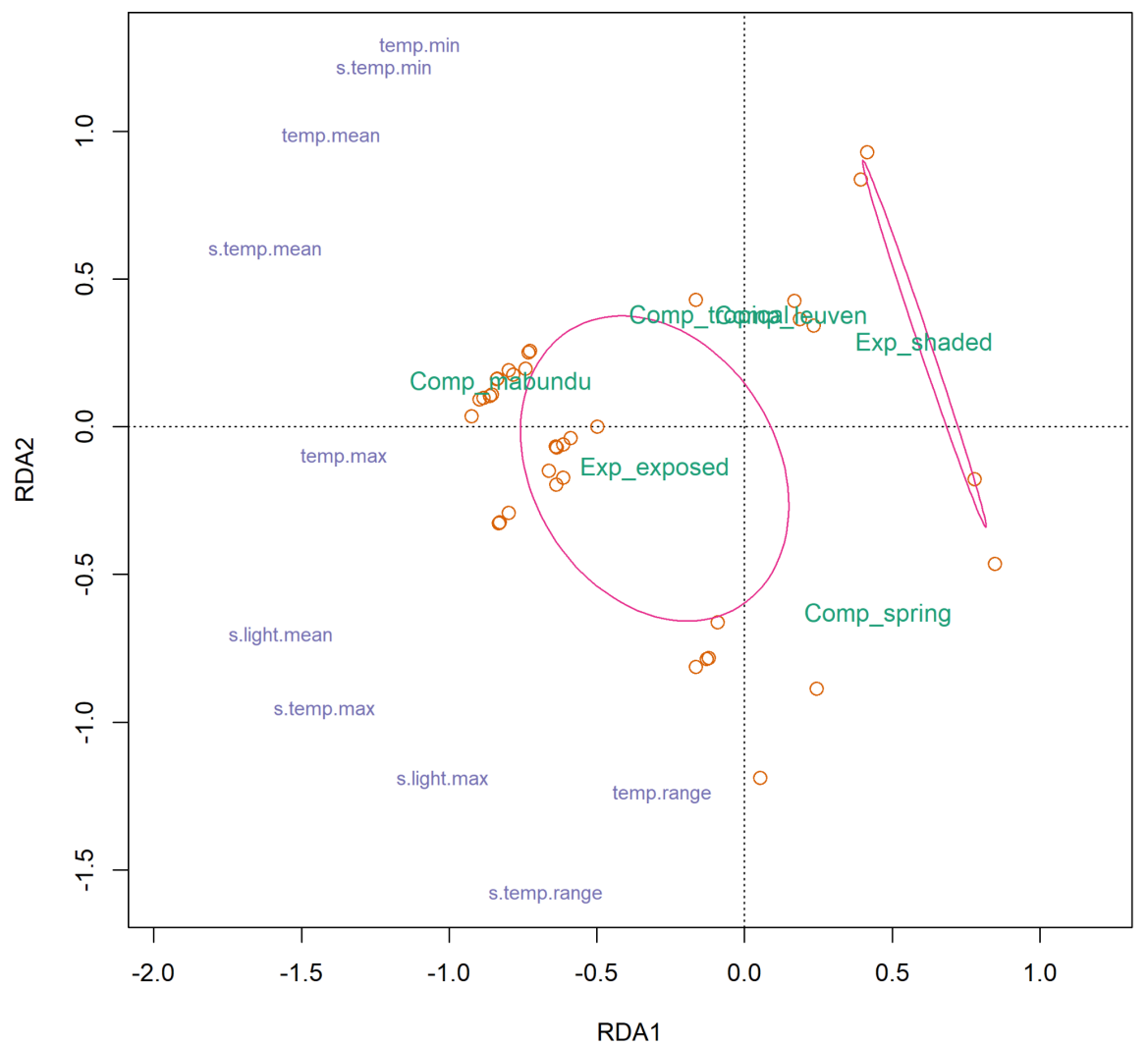

Fig. 2 Redundancy analysis ordination of microclimates used as simulated natural habitats in glass houses for seed germination experiments $\left(\mathrm{r}^{2}=0.88\right)$, ellipses are exposed and shaded sites (confidence limit $\left.=0.95\right)$, green text is explanatory factors (Comp=compartment, Exp=level of exposure to sun), blue text are microclimate variables achieved from data loggers at site ( $\mathrm{s}=$ from data logger at soil surface, temp=temperature).

Shaded microclimates obviously received less light intensity (731 \pm 240 lux shaded, $4491 \pm 1621$ lux exposed) (Fig. S1) and had a lower maximum temperature $\left(25.8 \pm 1.0^{\circ} \mathrm{C}\right.$ shaded, $\left.40.7 \pm 7.1^{\circ} \mathrm{C}\right)$. In the soil, the maximum temperature, again, was less at shaded sites compared to exposed sites $\left(19.5 \pm 2.2^{\circ} \mathrm{C}\right.$ shaded, $27.1 \pm 4.6^{\circ} \mathrm{C}$ exposed). The relationship between light intensity and temperature at the soil surface was asymptotic, above 2000 lux there was very little increase in temperature (Fig. S2).

\section{Effects of microclimate factors on seed germination}

In simulated-NHs, no seeds germinated in any shaded microclimates. These were then excluded from statistical analysis. Compartment and depth remained in the MAM, species and year were excluded after testing (Fig. 3a). Seeds had significantly higher probability of germinating in the two compartments that have a higher heating regime (compartments Mabundu, $\mathrm{z}=4.531, \mathrm{p}<0.001$, and Tropical $\mathrm{z}=6.586, \mathrm{p}<0.001$ ). Across all rooms, shallower buried seeds were more likely to germinate $(\mathrm{z}=6.491, \mathrm{p}<0.001)$.

Seedling emergence happened sooner after sowing in the compartments with warmer heating regimes (Mabundu, $\mathrm{t}=8.557, \mathrm{p}<0.001$ and Tropical 6.805, $\mathrm{p}=<0.001$, Fig. 3b). Predictably, shallow buried seeds at 1 $\mathrm{cm}$ emerged quicker than those buried at $7 \mathrm{~cm}(\mathrm{t}=2.657, \mathrm{p}=0.010)$. There was no effect of species on time to germination (seedling emergence), so this was excluded from the model, leaving compartment and burial-depth.

Synchronization was significantly greater in the cooler compartments (Spring and Leuven) for M. balbisiana (Fig. 3c), particularly in the pairwise contrast between Leuven and Mabundu $(\mathrm{z}=3.110, \mathrm{p}=0.010)$. 

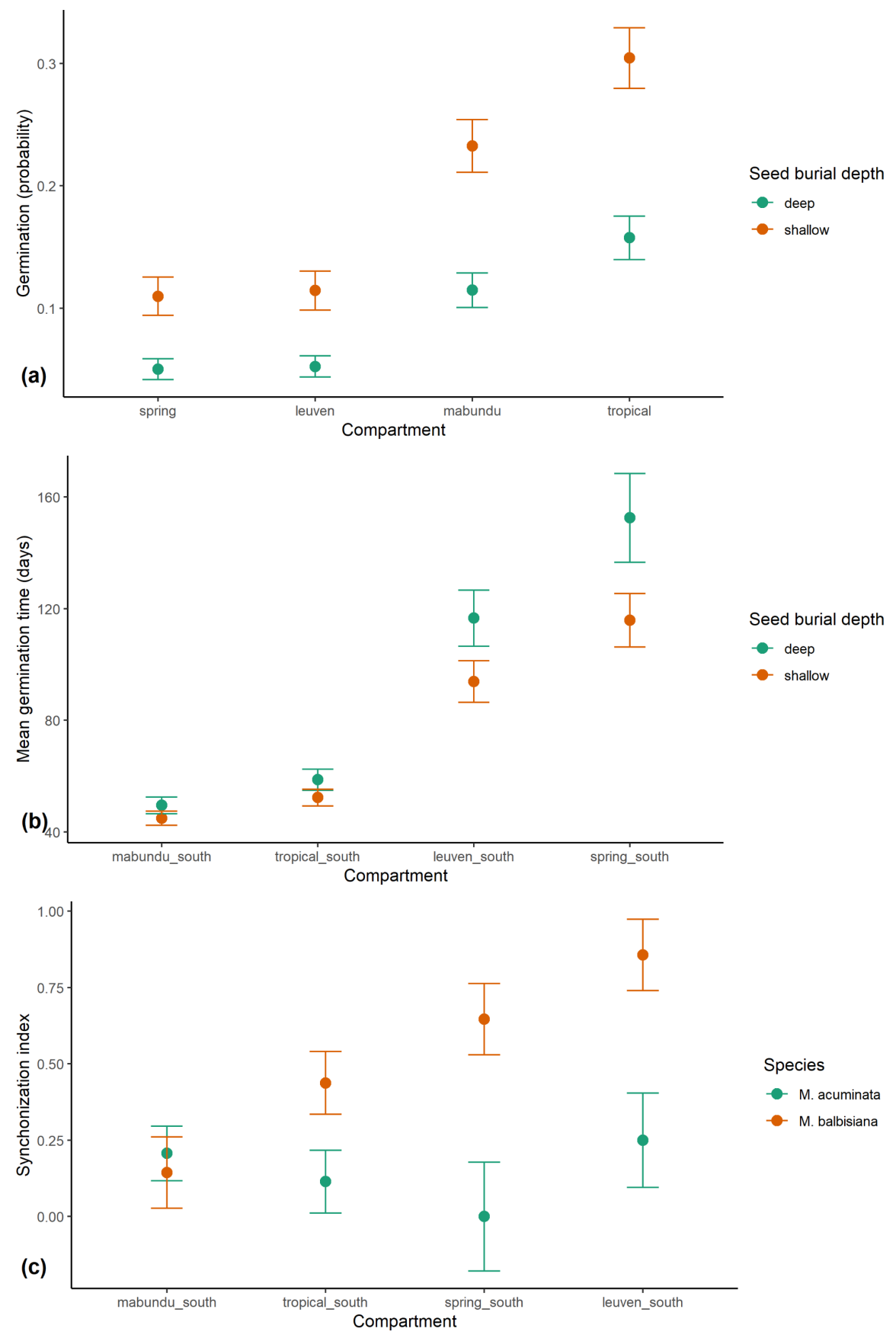

Fig. 3 Estimated marginal means of minimal adequate GLMs on germination of Musa seeds buried in Simulated-NHs in Belgium (a) Binomial germination outcome; (b) mean germination time; (c) synchronization index.

Effects of microclimate variables on seed germination

The effect of each microclimate variable on final germination percentage was visualized (Fig. S3). These were then used to estimate breakpoints on GLMs produced from binomial germination outcomes (Fig. 4). Results of this show temperatures (at seed burial level) operate a threshold mechanism, above which germination 
increases linearly (on the logit scale), within the limits of temperatures achieved in simulated-NHs. Therefore, for germination to occur mean soil temperature needs to be above $19^{\circ} \mathrm{C}$, maximum temperature above $23^{\circ} \mathrm{C}$, minimum temperature has much less of an effect. At the soil surface, the effect of mean temperature is positively linear to an optimal $24^{\circ} \mathrm{C}$ after which germination is reduced. The effect of maximum temperature is positive above a threshold of $28^{\circ} \mathrm{C}$. Germination increases with soil surface minimum temperature to $15^{\circ} \mathrm{C}$, then the positive slope is less steep. Soil warming relates to light intensity asymptotically (as described above); germination increased above 1076 lux (mean). In relation to maximum light intensity, germination increased to a breakpoint at 54000 lux, after which the effect on germination is negative. Comparisons of AICs of these models (Table S1) show at seed burial level the maximum temperature is the best fit; at soil surface level mean temperature is the best fit, and mean light intensity is a better fit than the maximum value during cue periods.
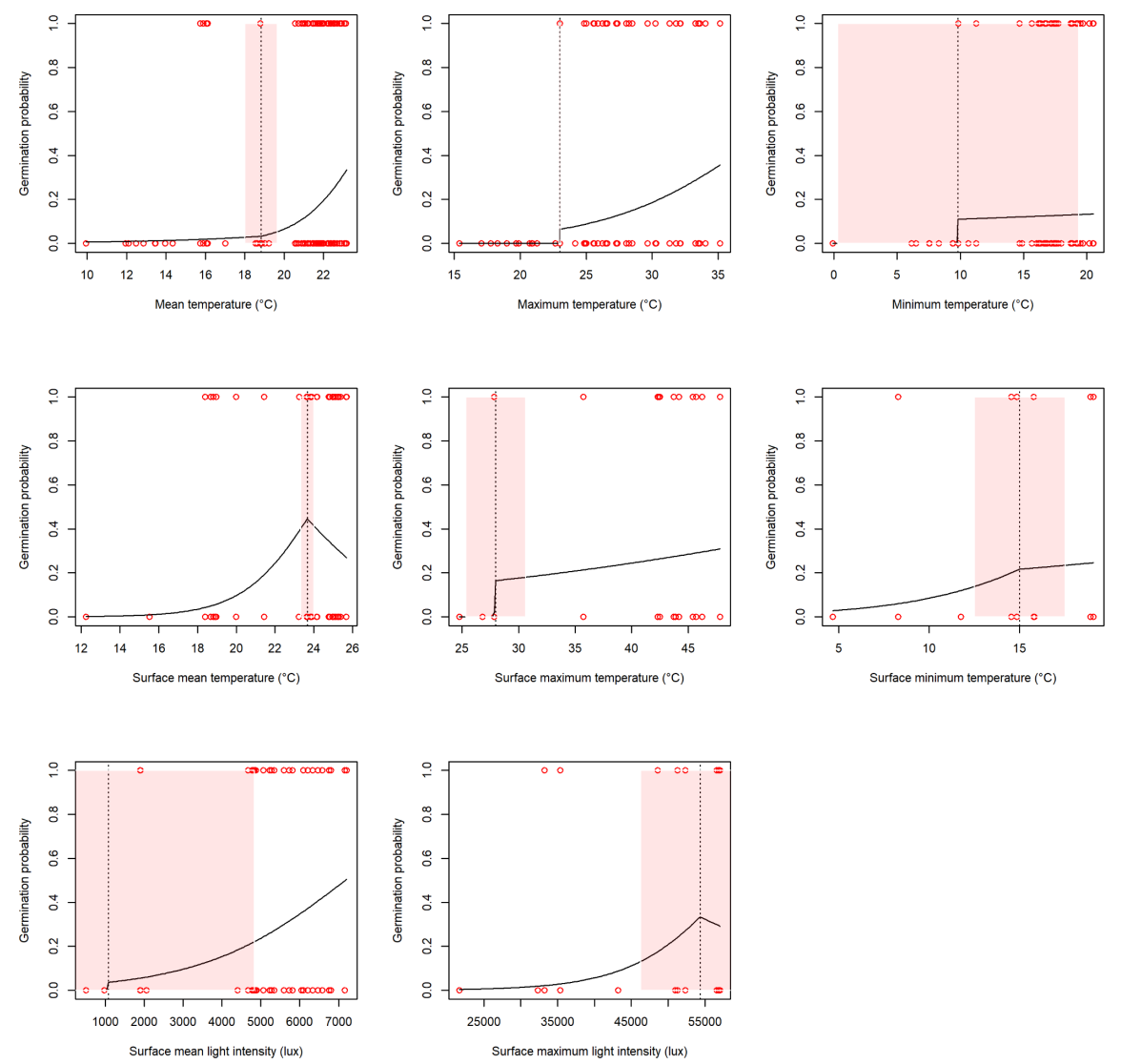

Fig. 4 Segmented GLMs of binomial germination outcomes back-transformed to the response probability scale as response to microclimate variables in simulated-NHs, dashed lines are breakpoints and pink shading is standard error (0.95), residuals are red circles.

\section{Survival and dormancy loss in the soil}

Overall, $40 \%$ of seeds that were buried in the soil for two years and $68 \%$ for one year were successfully exhumed from the soil. The probability of finding seeds was modelled against year, burial-depth, and accession (Fig. 5a). Seed burial-depth was the most important factor, deep-buried seeds were more likely to be successfully exhumed $(\mathrm{z}=16.722, \mathrm{p}<0.001)$, followed by year $(\mathrm{z}=13.379,<0.001)$. Surprisingly, seeds with low viability when sown had high probability of being exhumed (bur60 $\mathrm{z}=7.242, \mathrm{p}<0.001$, sia61 z=7.025, $\mathrm{p}<0.001$ ).

Viability of exhumed seeds were tested by TTC and incubation. Viability tests from these, original ER and 
maximum in Simulated-NHs, was modelled in a GLM. In contrast to the results of the above, accession was excluded from the MAM, year remained. Contrasts were made per year against original ER. Viability from the incubator test was not lost during one year in the soil. After two years in the soil, viability was reduced in both incubator and TTC tests. The TTC test consistently underestimated viability.

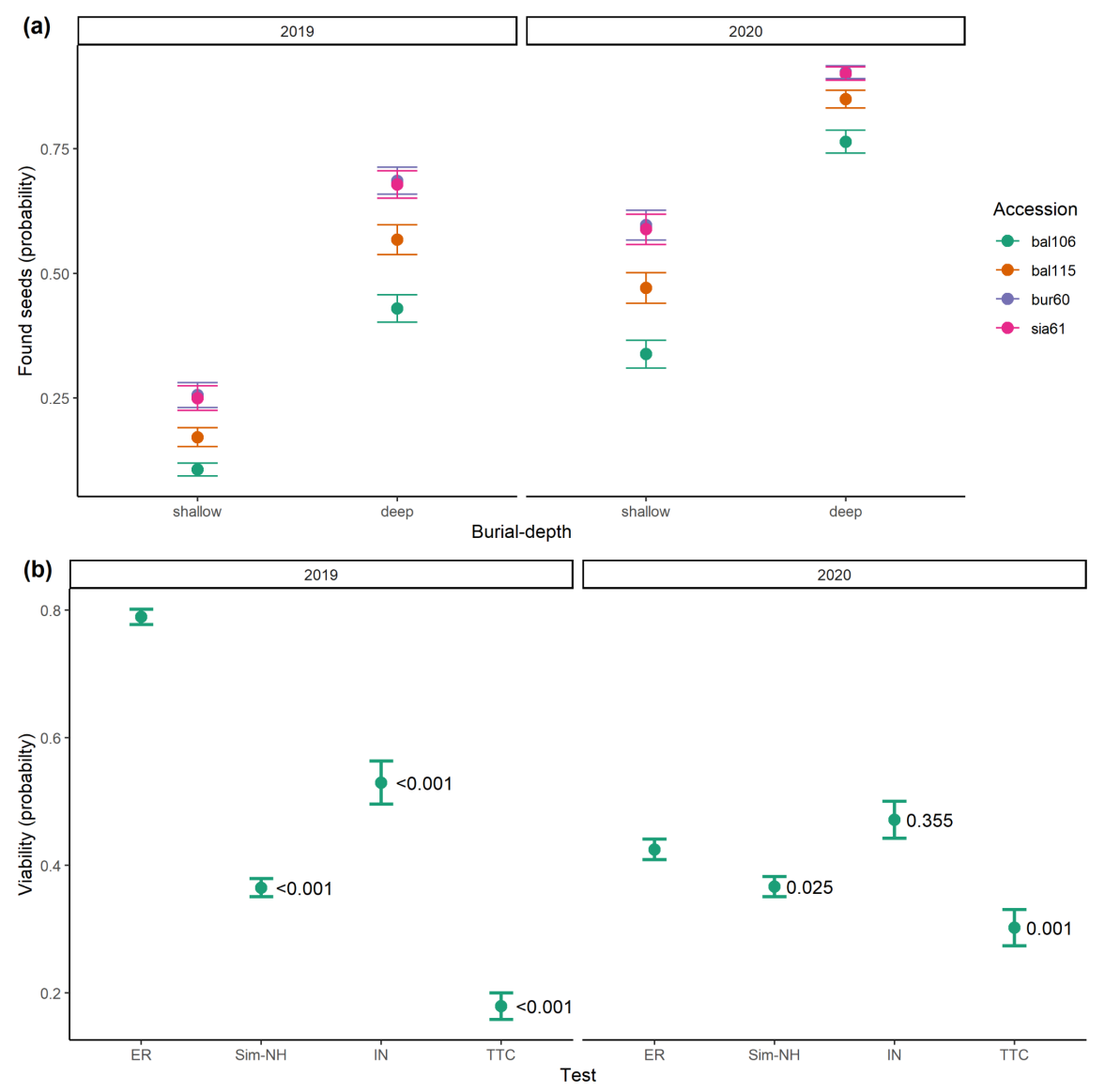

Fig. 5 Seed survival in the soil; (a) Probability of finding seeds in 2021 that were sown in 2019 and 2020 according to burial-depth and accession; (b) viability of seeds found in 2021 using a germination test in an incubator (IN) and the tetrazolium chloride test (TTC), with reference to viability at the start of the experiment using embryo rescue techniques (ER), and maximum germination achieved in a Simulated-NH; $\mathrm{p}$ values show contrasts (Dunnett test) against original viability (ER) for each year.

Seeds that were removed from storage and incubated under suitable conditions $\left(20 / 35^{\circ} \mathrm{C}\right)$, displayed dormancy i.e., they did not germinate at all. However, if they were buried in the soil at $7 \mathrm{~cm}$ for up to three months, germination significantly increased to probability $0.4(\mathrm{t}=2.518, \mathrm{p}=0.021$, Fig. 6$)$. 


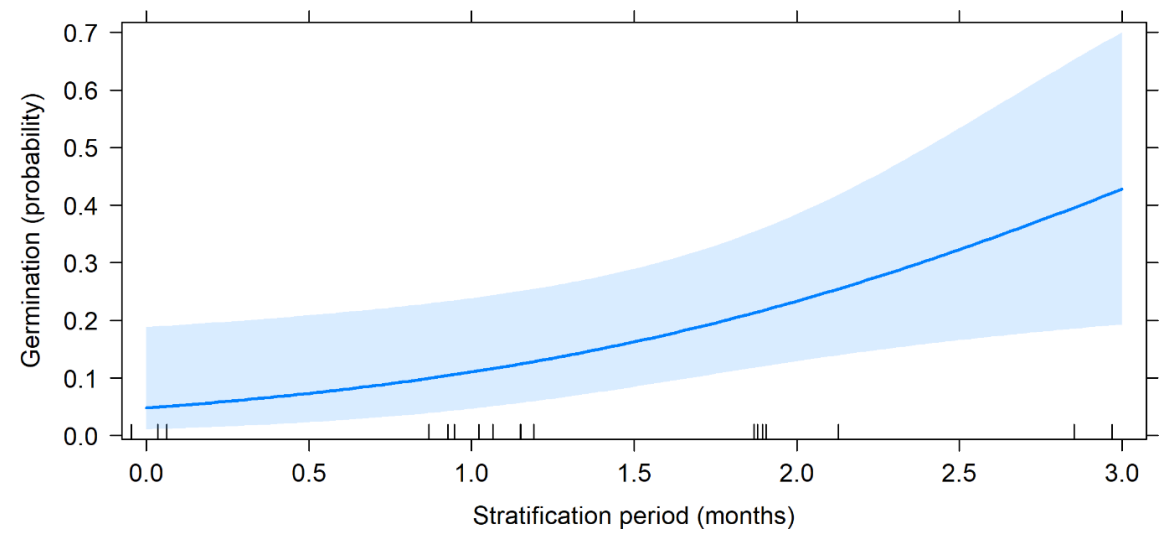

Fig. 6 Germination probability in an incubator (at $35 / 20{ }^{\circ} \mathrm{C}$, light/dark, $18 / 6$ hours cycled) of seeds buried and then exhumed from the soil for up to three months. Seeds were buried in the exposed Spring compartment.

\section{Discussion}

1. Use of semi-natural and simulated habitats for germination ecology experiments

In the present study we used a Semi-NH from the native range of $M$. balbisiana, and several Simulated$\mathrm{NHs}$ in glass houses located in a temperate region, to examine wild banana seed germination ecology. We established that with such approximations of NHs, it is possible to link germination responses to ecological factors such as foliar-shading and burial-depth. Hence with this approach we overcame limitations when access to experimental NHs was not possible, this allowed for greater ecological interpretation than with LCs alone.

\section{Temperature}

We found that Musa seed germination is stimulated by exposure to the sun. It was the maximum part of the temperature fluctuation, in our results, that is most closely associated with germination. Above the threshold of $23^{\circ} \mathrm{C}$, germination increased to a maximum at $35^{\circ} \mathrm{C}$ (in Simulated-NHs and $42^{\circ} \mathrm{C}$ in Semi-NHs) in exposed conditions. Our findings are broadly consistent with previous LC results, where optimal maximal and minimal temperature for germination were diurnal cycles of $35 / 18-20^{\circ} \mathrm{C}$ respectively, for both $M$. acuminata and M. balbisiana (Stotzky \& Cox 1962; Kallow et al. 2021). Interactions between the elements of warming and cooling cycles play an important role in simulating germination.

\section{Light}

One might think that as germination responses were directly associated with soil exposure to sun and, in simulated-NHs, light intensity, germination is stimulated by light. Additionally, we also found that seeds germinated to a greater extent from $1 \mathrm{~cm}$ compared to $7 \mathrm{~cm}$. However, light waves cannot usually penetrate the soil to greater than 4-5 mm depth (depending on soil moisture and particle size), and not to any amount that can illicit germination responses to light sensitive seeds (Woolley \& Stoller 1978; Tester \& Morris 1987), but in our experiment, seeds germinated from a depth of $7 \mathrm{~cm}$. We therefore infer that whilst Musa seed germination may be correlated with factors associated with light (light intensity, shallow burial) theses are correlations rather than causal, and it is temperature that regulates germination.

\section{Gap detection}

Musa seed germination in response to sun exposure demonstrates adaptation to detect suitable niches for seedling establishment following disturbance in forest NHs. Conversely, inhibition of germination in shade is also an adaptation for seedling survival (Kos \& Poschlod 2007; Poschlod et al. 2013). Musa germination 
responses were sensitive to sun/shade even when microclimates were very similar. For instance, mean temperatures were the same and range differed by only a few degrees in sun and shaded semi-NHs. Germination is therefore finely tuned to respond to microclimate such as that which would occur when a forest gap is formed (Pearson et al. 2002; Pearson et al. 2003). The effect of forest disturbance on temperature dynamics was studied by Harwick et al . (2015). The authors measured soil (10 cm depth) and air temperature (1.5m height) at three levels of forest disturbance in Borneo. Diurnal temperatures in oil palm plantations (formerly forested) were around $7^{\circ} \mathrm{C}$ greater at the hottest part of the cycle compared to old growth forests and soil temperatures were around $3{ }^{\circ} \mathrm{C}$ warmer at this point and around $1{ }^{\circ} \mathrm{C}$ cooler in the night; these were similar to our results in semi-NHs. Temperatures in logged forests were somewhat in between these two, but more similar to old growth forest. One could imagine that even in small forest gaps, microclimates could therefore also vary considerably (Pearson et al. 2002). These responses are in line with adaptations of other disturbance-adapted species that also require alternating temperature cycles rather than constant temperatures to germinate (Vázquez-Yanes \& Orozco-Segovia 1982; Vazquez-Yanes \& Orozco-Segovia 1993; Pearson et al. 2002; Seiwa et al.2009).

\section{Seed burial-depth}

When seeds were in the shade, burial-depth made no difference to germination, they did not germinate irrespective of burial-depth. In exposed sites, shallow buried seeds were more likely to germinate than deeply buried seeds. This was because temperature dynamics are likely buffered by burial depth. For some species, sensitivity to alternating temperatures is an adaptation to detect burial depth (Thompson, Grime \& Mason 1977; Thompson \& Grime 1983). Pearson et al. (2002) found, for large-seeded species, diurnal temperature sensitivity was more likely to related to forest gap size than seed burial-depth. This was also the case for large-seeded Musa, in that exposure was by far the most significant factor in simulated-NHs, and burial-depth was only secondary. For small seeds it is important to detect burial-depth as seedlings must reach the surface with small endosperm reserves; for larger seeds with greater nutrient reserves this is less of a limiting factor for survival.

\section{Survival and dormancy loss in the soil}

We found seeds can persist and remain viable buried in the soil for at least two years. In fact, there was no loss of viability after one year, there was however loss of actual seeds. Seed loss was more pronounced with shallow burial, suggesting it is the result of predation or perhaps splashing during watering, rather than decomposition. This is also supported by the fact that accessions with less viable seeds were more likely to be found i.e., seeds were not lost by decomposition of dead seeds.

For seeds adapted to disturbance, seed persistence in the soil seed bank is important. Musa clearly invest considerably in seed coat defenses (Graven et al. 1996), to survive the intense pressure present in the soil community (Dalling et al. 2011).

Not only do seeds persist in the soil, but dormancy is reduced during this process. In our results, when seeds were stratified for three months, or when they were in the soil for a year, germination increased. A stratification requirement is in keeping with results from our previous study (Kallow et al. 2021). Although, stratification was not required for freshly extracted M. balbisiana seeds in Semi-NHs, implying drying induces secondary dormancy in Musaseeds, as proposed by Chin (1996).

There was greater germination synchronization in cooler Simulated-NHs as seeds responded to threshold temperatures when sun was stronger during the summer. When temperatures were consistently warmer, synchronicity was reduced - this may again be a disturbance adaptation. We found this response more evident in M. balbisiana than in M. acuminata, suggesting it may also relate to seasonality as $M$. balbisiana has a large distribution that includes subtropical seasonal climates (Mertens et al. 2021). 


\section{Conclusions}

Studying germination ecology has intrinsic challenges, possibly the biggest being access to seeds and experimental set-ups in suitable conditions and timeframes. In the present study we demonstrate an approach for dealing with such difficulties in studying tropical seed germination ecology, which is a challenge when researchers are outside of a plant's native region. Using Semi-NHs and Simulated-NHs we found: (1) foliageshading inhibits germination of non-dormant seeds, and exposure to sun stimulates germination; this response is most closely associated with maximum temperature variation found under direct sunlight; this effect is marginally buffered by deep burial in the soil; (2) freshly extracted seeds are non-dormant, but stored seeds lose their dormancy during burial in the soil; (3) Musa seeds remain viable in the soil for at least a year without any loss in viability. Thus, wild banana species are well adapted to exploit canopy gaps following disturbance.

\section{Acknowledgments}

We thank Isla Kallow, Jasmin Kallow, Manuela Garcia Zuluaga and Kevin De Pauw for assisting with the setting up the glass house experiments. We gratefully acknowledge the help of John Mark Barios, Lyka Yanos and Paulo Jerome Lopez at NPGRL for setting up and monitoring the germination experiments in the Philippines and for Michelle Lyka V. Descalsota for assistance in viability assessing seed collections at NPGRL. We also thank the late Daniele Roques (CIRAD, Centre de Ressources Biologiques Plantes Tropicales (CRB-PT), Guadeloupe), Josephine Agogbua (International Institute of Tropical Agriculture (IITA), Nigeria) and Zhiying Li (Institute of Tropical Crop Genetic Resources, CATAS Tropical Crops, Danzhou, China) for providing seeds to use. This work was funded as a sub-grant from the University of Queensland from the Bill \& Melinda Gates Foundation project 'BBTV mitigation: Community management in Nigeria, and screening wild banana progenitors for resistance' [OPP1130226]. The authors thank all donors who supported this work also through their contributions to the CGIAR Fund (http://www.cgiar.org/funders), and in particular to the CGIAR Research Program Roots, Tubers and Bananas (RTB-CRP). This study was supported by a bilateral grant between the Research Foundation - Flanders (FWO-Vlaanderen) and the Vietnamese National Foundation for Science and Technology Development (NAFOSTED) under grant number G0D9318N.

\section{Author contributions}

SK: conceptualization, methodology, software, formal analysis, investigation, data curation, writing-original draft, writing-review and editing, visualization; KQ: investigation; BP: conceptualization, methodology, resources, writing-review and editing, supervision, funding acquisition; SBJ: conceptualization, methodology, resources, writing-review and editing, supervision, funding acquisition; JD: writing-review and editing, supervision, funding acquisition; LG: resources; RS: writing-review and editing, supervision; FV: conceptualization, methodology, resources, writing-review and editing.

\section{Conflict of interest}

The authors declare that there is no conflict of interest associated with this article and research.

\section{Data availability}

All data available at Kallow, Simon (2021): Using semi-natural and simulated habitats for seed germination ecology. figshare. Dataset. https://doi.org/10.6084/m9.figshare.14884470.v1 


\section{Supplementary figures and tables}

Fig. S1. Average and standard deviations of temperature and light intensity during cue periods of exposed and shaded environments, temperatures are $\operatorname{deg} \mathrm{C}$, light intensity is lux.

Fig. S2. Light intensity and temperature measured at simulated natural environments in glass houses during germination tests; asymptotic non-linear regression shown (residual standard error 4.119 on 417,661 degrees of freedom).

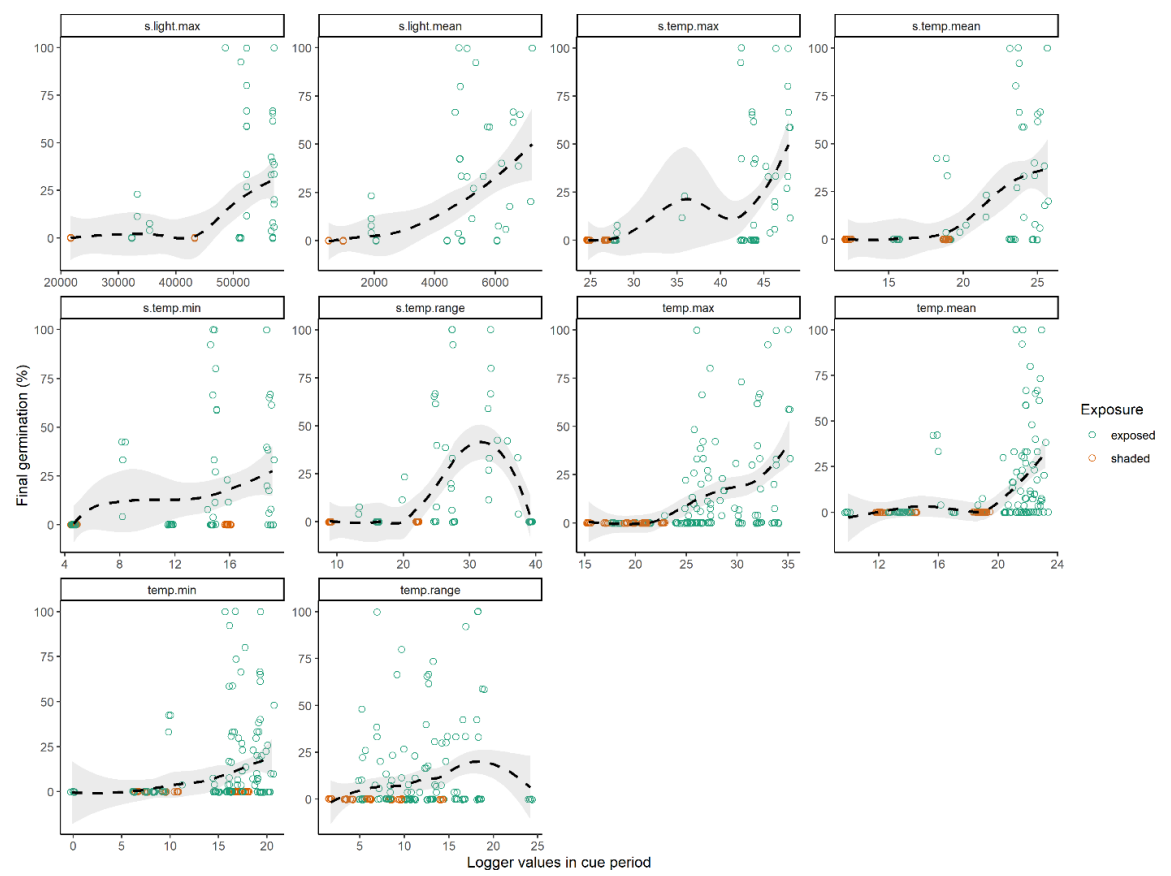

Fig. S3. Final germination percentages and microclimate variables from simulated-NHs, dashed trend lines plotted with Loess non-parameter regression, shaded area is $95 \%$ standard error, light variables are in lux, temperature are ${ }^{\circ} \mathrm{C}, \mathrm{s}=$ value from logger at the soil surface, otherwise they are at seed burial depth.

Table S1. Model fits of germination outcome in response to microclimate variables in simulated-NHs in segmented GLMs.

\begin{tabular}{llll}
\hline Variable & AIC & Residual deviance & df \\
\hline temp.mean & 1749 & 1741 & 3388 \\
temp.max & 1612 & 1604 & 3388 \\
temp.min & 1890 & 1882 & 3388 \\
s.temp.mean & 799 & 791 & 1220 \\
s.temp.max & 817 & 810 & 1220
\end{tabular}




\begin{tabular}{llll}
\hline Variable & AIC & Residual deviance & df \\
\hline s.temp.min & 961 & 953 & 1220 \\
s.lightemp.mean & 803 & 796 & 1220 \\
s.lightemp.max & 887 & 880 & 1220 \\
\hline
\end{tabular}

\section{Literature cited}

Amah, D., Turner, D.W., Gibbs, J., Waniale, A., Gram, G. \& Swennen, R. (2020) Overcoming the fertility crisis in bananas (Musa spp.).Achieving sustainable cultivation of bananas (eds G.H.J. Kema \& A. Drenth). Burleigh Dodds, Cambridge, UK.

Baskin, C.C. \& Baskin, J.M. (2014) Seeds: Ecology, biogeography and evolution of dormancy and germination . Academic Press, San Diego.

Batte, M., Swennen, R., Uwimana, B., Akech, V., Brown, A., Tumuhimbise, R., Hovmalm, H.P., Geleta, M. \& Ortiz, R. (2019) Crossbreeding East African Highland Bananas: Lessons learnt relevant to the botany of the crop after 21 years of genetic enhancement. Frontiers in Plant Science, 10, 81.

BGCI (2021) GardenSearch online database. Botanic Gardens Conservation International, Richmond, U.K.

Chin, H.F. (1996) Germination and storage of banana seeds. New frontiers in resistance breeding for Nematode, Fusarium and Sigatoka(eds E.A. Frison, J.P. Horry \& D.D. Waele), pp. 218-229. International Plant Genetic Resources Institute, International Network for the Improvement of Banana and Plantain, Kuala Lumpur, Malaysia.

Czabator, F.J. (1962) Germination value: an index combining speed and completeness of pine seed germination. Forest Science, 8, 386-396.

Dalling, J.W., Davis, A.S., Schutte, B.J. \& Arnold, A.E. (2011) Seed survival in soil: interacting effects of predation, dormancy and the soil microbial community. Journal of Ecology, 99, 89-95.

De Langhe, E., Vrydaghs, L., De Maret, P., Perrier, X. \& Denham, T. (2009) Why bananas matter: an introduction to the history of banana domestication. Ethnobotany Research and Applications, 7,165-177.

Dempewolf, H., Baute, G., Anderson, J., Kilian, B., Smith, C. \& Guarino, L. (2017) Past and future use of wild relatives in crop breeding. Crop Science, 57, 1070-1082.

Dinsdale, J.M., Dale, M.P. \& Kent, M. (2000) Microhabitat availability and seedling recruitment of Lobelia urens: a rare plant species at its geographical limit. Seed Science Research, 10, 471-487.

European Investment Bank (2018) Environmental and social standards. Luxembourg.

FAO (2014) Genebank standards for plant genetic resources for food and agriculture. FAO, Rome.

Faraji, L. \& Karimi, M. (2020) Botanical gardens as valuable resources in plant sciences. Biodiversity and Conservation .

Govaerts, R. \& Häkkinen, M. (2006) World Checklist of Musaceae. Royal Botanic Gardens, Kew, Richmond, UK.

Graven, P., De Koster, C.G., Boon, J.J. \& Bouman, F. (1996) Structure and macromolecular composition of the seed coat of the Musaceae. Annals of Botany, 77, 105-122.

Kaeberlein, T., Lewis, K. \& Epstein, S.S. (2002) Isolating "uncultivable" microorganisms in pure culture in a simulated natural environment. Science, 296, 1127. 
Kallow, S., Davies, R., Panis, B., Janssens, S.B., Vandelook, F., Mertens, A., Swennen, R., Tahir, M.B. \& Dickie, J. (2021) Regulation of seed germination by diurnally alternating temperatures in disturbance adapted banana crop wild relatives (Musa acuminata ). Seed Science Research, 30, 1-11.

Kallow, S., Longin, K., Sleziak, N.F., Janssens, S.B., Vandelook, F., Dickie, J., Swennen, R., Paofa, J., Carpentier, S. \& Panis, B. (2020) Challenges for ex situ conservation of wild bananas: seeds collected in Papua New Guinea have variable levels of desiccation tolerance.Plants, 9, 1243.

Kos, M. \& Poschlod, P. (2007) Seeds use temperature cues to ensure germination under nurse-plant shade in xeric Kalahari savannah. Annals of Botany, 99, 667-675.

Labouriau, L.G. \& Valadares, M.E.B. (1983) The germination of seeds . OEA., Washington DC.

Lenth, R.V. (2020) Emmeans: Estimated marginal means, aka least-squares means. CRAN.

Lozano-Isla, F., Benites-Alfaro, O. \& Pompelli, M.F. (2019) GerminaR: An R package for germination analysis with the interactive web application "GerminaQuant for R". Ecological research,32, 339-346.

Mattana, E., Picciau, R., Puddu, S., Cuena Lombraña, A. \& Bacchetta, G. (2016) Effect of temperature and cold stratification on seed germination of the Mediterranean wild aromatic Clinopodium sandalioticum (Lamiaceae). Plant Biosystems - An International Journal Dealing with all Aspects of Plant Biology, 150, 846-850.

Mertens, A., Swennen, R., Rønsted, N., Vandelook, F., Panis, B., Sachter-Smith, G., Vu, D.T. \& Janssens, S.B. (2021) Conservation status assessment of banana crop wild relatives using species distribution modelling. Diversity and Distributions, 27, 729- 746.

Mounce, R., Smith, P. \& Brockington, S. (2017) Ex situ conservation of plant diversity in the world's botanic gardens. Nature Plants,3, 795-802.

Muggeo, V.M. (2017) Interval estimation for the breakpoint in segmented regression: a smoothed score-based approach. Australian \& New Zealand Journal of Statistics, 59, 311-322.

Oksanen, J., Blanchet, F.G., Friendly, M., Kindt, R., Legendre, P., McGlinn, D., Minchin, P.R., O’Hara, R.B., Simpson, G.L., Solymos, P., Stevens, M.H.H., Szoecs, E. \& Wagner, H. (2019) vegan: community ecology package. CRAN.

Panis, B., Kallow, S. \& Janssens, S.B. (2020) Seed germination, preservation and population genetics of wild Musa germplasm.Achieving sustainable cultivation of bananas (eds G.H.J. Kema \& A. Drenth). Burleigh Dodds, Cambridge, UK.

Pearson, T.R.H., Burslem, D., Mullins, C.E. \& Dalling, J.W. (2002) Germination ecology of neotropical pioneers: Interacting effects of environmental conditions and seed size. Ecology, 83,2798-2807.

Pearson, T.R.H., Burslem, D., Mullins, C.E. \& Dalling, J.W. (2003) Functional significance of photoblastic germination in neotropical pioneer trees: a seed's eye view. Functional Ecology,17, 394-402.

Perez, T.M., Valverde-Barrantes, O., Bravo, C., Taylor, T.C., Fadrique, B., Hogan, J.A., Pardo, C.J., Stroud, J.T., Baraloto, C. \& Feeley, K.J. (2019) Botanic gardens are an untapped resource for studying the functional ecology of tropical plants. Philosophical Transactions of the Royal Society B: Biological Sciences, 374, 20170390.

Poschlod, P., Abedi, M., Bartelheimer, M., Drobnik, J., Rosbakh, S. \& Saatkamp, A. (2013) Seed ecology and assembly rules in plant communities. Vegetation ecology (eds E. van der Maarel \& J. Franklin), pp. 164-202. Wiley, Chichester.

Primack, R.B. (1980) Variation in the phenology of natural populations of montane shrubs in New Zealand. 68, 862 . 
R Core Team (2020) R: A language and environment for statistical computing. R Foundation for Statistical Computing, Vienna, Austria.

Ranal, M.A. \& Santana, D.G.D. (2006) How and why measure the germination process? Revista Brasileira de Botanica, 29,1-11.

Seiwa, K., Ando, M., Imaji, A., Tomita, M. \& Kanou, K. (2009) Spatio-temporal variation of environmental signals inducing seed germination in temperate conifer plantations and natural hardwood forests in northern Japan. Forest Ecology and Management,257, 361-369.

Singh, S., Agrawal, A., Kumar, R., Thangjam, R. \& John, K.J. (2021) Seed storage behavior of Musa balbisiana Colla, a wild progenitor of bananas and plantains - Implications for ex situ germplasm conservation. Scientia Horticulturae, 280, 109926.

Stephens, E.L., Castro-Morales, L. \& Quintana-Ascencio, P.F. (2012) Post-dispersal seed predation, germination, and seedling survival of five rare Florida scrub species in intact and degraded habitats.American Midland Naturalist, 167, 223-239.

Stotzky, G., Cox, E. \& Goos, R. (1961) Alternating temperature requirements for the germination of Musa balbisiana Colla seeds.Plant Physiology, 36, 21-22.

Stotzky, G. \& Cox, E.A. (1962) Seed germination studies in Musa . II. Alternating temperature requirement for the germination of Musa balbisiana. American Journal of Botany, 49,763-770.

Tester, M. \& Morris, C. (1987) The penetration of light through soil.Plant, Cell \& Environment, 10, 281-286.

Thompson, K. \& Grime, J. (1983) A comparative study of germination responses to diurnally-fluctuating temperatures. Journal of Applied Ecology, 20, 141-156.

Thompson, K., Grime, J. \& Mason, G. (1977) Seed germination in response to diurnal fluctuations of temperature. Nature, $\mathbf{2 6 7 , 1 4 7 .}$

UN General Assembly (2015) Transforming our world: the 2030 Agenda for Sustainable Development.

Vázquez-Yanes, C. \& Orozco-Segovia, A. (1993) Patterns of seed longevity and germination in the tropical rainforest. Annual review of ecology and systematics, 24, 69-87.

Vázquez-Yanes, C. \& Orozco-Segovia, A. (1982) Seed germination of a tropical rain forest pioneer tree (Heliocarpus donnell-smithii) in response to diurnal fluctuation of temperature. Physiologia plantarum, 56, 295-298.

Woolley, J.T. \& Stoller, E.W. (1978) Light penetration and light-induced seed germination in soil. Plant Physiology, 61, 597-600. 